Fifth Symposium of Risk Analysis and Risk Management in Western China (WRARM 2017)

\title{
The Research of Nonlinear Effect on Financial Poverty Alleviation of Guizhou Province
}

\author{
Jianchun Yang \\ School of Business Management, Guizhou University of Finance and Economics, Guiyan \\ 550025, China
}

\begin{abstract}
Based on the model structured of testing nonlinear effect on financial poverty alleviation, applying Granger causality test and regression analysis to analyzing the nonlinear relationship between financial development and poverty alleviation in Guizhou Province, and it is showed that such relationship follows Kuznets Curve characterized by invert-U relationship, namely with the nonlinear effect of worsening first before improvement found in such relationship. Deeply analyze on which and give proposals, so as to help provide references in making policy within related work of financial poverty alleviation in Guizhou Province.
\end{abstract}

Keywords

Financial development; Poverty alleviation; Kuznets Curve

\section{贵州省金融减贫的非线性效应研究}

\author{
杨建春 \\ 贵州财经大学工商学院, 贵阳 550025, 中国
}

摘要：在构建检验金融减贫非线性效应模型的基础上,运用 Granger 因果检验、回归分析等方 法分析贵州省金融发展与贫困减缓的非线性关系。结果显示贵州省金融发展与贫困减缓之间 遵循库兹涅茨 “倒 U 型” 曲线关系，即金融发展与贫困减缓之间存在先恶化后改善的非线 性效应。在计量分析基础上进行深入分析并提出发展建议，以期为贵州省金融扶贫相关工作 的开展提供政策制定的参考依据。

关键词：金融发展；贫困减缓；库兹涅茨曲线

1. 引言

贵州省是全国贫困问题最突出的 欠发达省份。改革开放以来, 贵州扶 贫工作取得重大进展。从贫困人口数 
量来看, 按照国家贫困标准, 贵州省 贫困人口数量从 1978 年的 1587 万人 减少到 2007 年的 236 万人; 自 2008 年 国家正式采用低收人线取代绝对贫困 线以来，贵州省贫困人口数量由 2008 年的 626 万人减少到 2010 年的 421 万 人; 自 2011 年国家采用 2300 元/ 人・年的贫困线以来，贵州省贫困人 口数量由 2011 年的 1149 万人减少到 2015 年的 493 万人。从贫困发生率来 看，贵州省贫困发生率从1978 年的 $59.1 \%$ 下降到 2007 年的 $6.5 \%$ ：自 2008 年国家正式采用低收入线取代绝对贫 困线以来，贵州省贫困发生率由 2008 年的 $17.4 \%$ 下降到 2010 年的 $12.1 \%$; 自 2011 年国家采用 2300 元/人・年的 贫困线以来，贵州省贫困发生率由 2011 年的 $33.1 \%$ 减少到 2015 年的 $14.03 \%$ 。然而, 贵州省仍然是我国 扶贫攻坚的主战场。新形势下贵州精 准扶贫进程面临诸多瓶颈和制约，依 然面临着经济建设落后、生态环境脆 弱、人口素质偏低、公共服务滞后等 问题和困难的挑战，其中融资约束问 题尤为突出。因此研究贵州省金融发 展与贫困减缓的关系, 对贵州省金融扶 贫相关工作的开展有着重要的现实意 义。

\section{2. 文献综述}

长期以来国内外学者对金融发展 与贫困减缓的关系都做了大量的研 究, 但由于模型、指标选取、测量误 差、数据异质性、相关解释变量等原 因导致分析的结果并不一致。通过梳 理发现主要形成了三种观点。第一种 观点认为金融发展与贫困减缓正相 关。Jalilian \& Kirkpatrick (2002)、 Akhter et al (2010)等通过分析发现金融 发展和贫困减缓之间的正相关关系, 认为金融发展对贫困减缓有利 ${ }^{[2][3]}$ 。第
二种观点认为金融发展与贫困减缓非 正相关。Fowowe \& Abidoye( 2013)认 为金融发展并没有改善贫困状况 ${ }^{[4]}$ 。

Seven \& Coskun(2016)通过动态面板数 据分析方法, 考察银行和股票市场的 发展是否有助于减少新兴国家的收入 不平等和贫困。研究结果表明, 尽管 金融发展促进了经济增长，但并不有 利于新兴国家的贫困人群, 无论是银 行还是股票市场都没有在减贫方面发 挥重要作用 ${ }^{[5]}$ 。第三种观点认为金融 发展与贫困减缓之间存在非线性关 系。Greenwood \& Jovanovic(1990)认为 金融发展与收入分配之间遵循库兹涅 茨 “倒 $U$ 型” 曲线关系, 因而通过收 入分配间接作用到贫困减缓上,也应存 在库兹涅茨曲线关系 ${ }^{[6]}$ 。崔艳娟(2014) 通过面板数据检验金融发展对贫困减 缓的作用，验证了 Greenwood \& Jovanovic 的预测 ${ }^{[7]}$ 。

金融发展与贫困减缓研究中的多 样化关系表现意味着研究还有进一步 深入的空间。从研究内容来看, 既有 文献关于金融发展与贫困减缓的因果 关系探讨较多，关于金融发展影响贫 困减缓的作用机制探讨较少 ${ }^{[7]}$; 从研 究方法来看, 大多数研究在线性模型


的研究较少; 从研究对象来看, 基于 国家层面的宏观研究较多, 对区域性 金融扶贫问题的研究较少。因而本文 将深入探讨贵州省金融发展与贫困减 缓之间的非线性关系，以期为贵州省 金融扶贫相关工作的开展提供政策制 定的参考依据。

\section{3. 模型构建与变量说明}

\section{1. 模型的构建}


为检验金融发展与贫困减缓之间 的非线性效应, 本文构建如下分析模 型:

$$
p o v_{t}=\alpha_{0}+\beta_{i} f i n_{t}+\beta_{2} f i n_{t}^{2}+\varepsilon_{t}
$$

pov $_{t}=\alpha_{0}+\beta_{i} f$ fin $_{t}+\beta_{2}$ fin $_{t}{ }^{2}+\beta_{3} \ln r j g d p_{t}+\beta_{4} c r_{t}{ }^{+} \varepsilon_{t}$

模型（1）检验金融发展对贫困减 缓的直接非线性效应, 直接效应主要 由贫困人口对金融产品服务的获取和 可及性决定。模型（2）检验金融发展 对贫困减缓的间接非线性效应，间接 效应指金融发展通过促进经济增长或 收入分配的改进, 进而减缓贫困 ${ }^{[9]}$ 。

$p o v 、 r j g d p 、 c r$ 分别表示贫困减缓、经 济增长、收人分配, fin 表示金融发展 变量,用金融发展规模(fir) 和金融发展效 率 $(f e)$ 两个指标分别进行考察。 $\varepsilon$ 是误 差项, $\alpha 、 \beta$ 是待估计系数, $\mathrm{t}$ 表示时 期。如果 $\beta 1>0, \quad \beta 2<0$, 则为 “倒 $\mathrm{U}$ 型” 关系; 如果 $\beta 1<0, \beta_{2}>0$, 则为 “正 $U$ 型” 关系; 如果 $\beta 2=0$, 则 为线性关系。

\section{2. 变量说明}

(1) 贫困减缓 $(p o v)$ 。关于贫困 水平的衡量指标主要有贫困发生率和 贫困距指数、森指数、FGT 指数等 ${ }^{[11]}$, 考虑到数据可得性以及研究时期 跨度较长，本文采用农村居民家庭恩 格尔系数作为衡量贫困水平的指标, 该指标越低则贫困减缓力度越大, 反 之亦然。

(2) 金融发展 (fin)。本文从金 融发展效率 (fe) 和金融发展规模 (fir) 两个方面分别衡量金融发展水平。以 贷款/储蓄存款比率衡量金融发展效率 (fe)，将金融机构的存贷款与地区生 产总值数据整理成金融相关比率, 衡 量金融发展规模 (fir)。

（3）经济增长 (rjgdp)。本文选 取人均 GDP 来衡量贵州的经济发展水 平。为减少变量数据波动幅度过大和
可能存在的异方差带来的影响, 对该 指标做对数处理。

(4) 收入分配 $(c r)$ 。关于收入分 配, 既有研究中常用泰尔指数、基尼 系数以及城乡居民人均收入比率计算 [7]。本文采用城镇居民人均可支配收 入/农村居民人均纯收入衡量收入分配 的城乡差距。

\section{4. 计量分析}

本文运用 Eviews 软件对数据进行 计量分析, 时间序列数据来源于《贵 州统计年鉴》, 数据取样时段为 19782016 年。

\section{1. 稳性检验}

采用 Dickey 和 Fuller 的增广单 位根 (ADF) 检验各时间序列数据的平 稳性, 单位根检验结果（见表 1) 显 示, pov、fir、fe、rjgdp、cr 在一阶 差分下均通过了显著性水平为 $1 \%$ 的 $\mathrm{ADF}$ 单位根检验, 说明各变量的一阶差 分序列为平稳序列。

\subsection{Granger 因果检验}

Granger 因果检验结果（见表 2) 显示, 贵州金融发展规模、金融发展 效率、经济增长是贫困减缓的 Granger 原因，金融发展规模与经济增长之间 存在双向 Granger 因果关系。揭示了 贵州金融发展对贫困减缓不仅有直接 的促进作用，而且还存在金融发展通 过促进经济增长进而减少贫困的间接 促进作用。同时, 结果显示收入分配 与贫困减缓之间不存在统计意义上的 Granger 因果关系，表明现阶段贵州省 金融发展通过改进收入分配进而减少 贫困的间接促进作用不明显。 
表 1 变量单位根检验结果

\begin{tabular}{|c|c|c|c|c|c|c|}
\hline \multirow{2}{*}{ 变量 } & \multirow{2}{*}{$\begin{array}{l}\text { 检验类型 } \\
(\mathrm{C}, \mathrm{T}, \mathrm{L})\end{array}$} & \multirow{2}{*}{$\begin{array}{c}\text { ADF } \\
\text { 检验值 }\end{array}$} & \multicolumn{3}{|c|}{ 各显著性水平下的临界值 } & \multirow{2}{*}{$\begin{array}{l}\text { 检验 } \\
\text { 结果 }\end{array}$} \\
\hline & & & $1 \%$ & $5 \%$ & $10 \%$ & \\
\hline Dpov & $(\mathrm{C}, \mathrm{T}, 0)$ & -6.093 & -4.227 & -3.537 & -3.200 & 平稳 \\
\hline Dfir & $(\mathrm{C}, \mathrm{T}, 3)$ & -4.378 & -4.253 & -3.549 & -3.207 & 平稳 \\
\hline Dfe & $(\mathrm{C}, \mathrm{T}, 0)$ & -6.184 & -4.227 & -3.537 & -3.200 & 平稳 \\
\hline Drjgdp & $(C, 0,0)$ & -3.715 & -3.621 & -2.943 & -2.610 & 平稳 \\
\hline Dcr & $(\mathrm{C}, \mathrm{T}, 0)$ & -4.566 & -4.227 & -3.537 & -3.200 & 平稳 \\
\hline
\end{tabular}

注: C: 含截距项; $\mathrm{T}$ : 含趋势项; L:滞后阶数; 变量前加 D 表示一阶差分。

表 2 Granger 因果检验结果

\begin{tabular}{|c|c|c|c|}
\hline 滞后阶数 & 零假设 & F 统计量 & P 值 \\
\hline Lags : & fir does not Granger Cause pov & 3.3025 & 0.0497 \\
\cline { 2 - 4 } & $p o v$ does not Granger Cause fir & 0.3827 & 0.6854 \\
\hline Lags: 2 & $f e$ does not Granger Cause pov & 3.5692 & 0.0400 \\
\cline { 2 - 4 } & $p o v$ does not Granger Cause fe & 0.5469 & 0.5841 \\
\hline Lags: 1 & Lnjgdp does not Granger Cause poV & 4.3345 & 0.0447 \\
\cline { 2 - 4 } & $p o v$ does not Granger Cause Lnjgdp & 2.0377 & 0.1623 \\
\hline \multirow{2}{*}{ Lags: 1 } & $c r$ does not Granger Cause pov & 1.1291 & 0.3359 \\
\cline { 2 - 4 } & $p o v$ does not Granger Cause cr & 0.4217 & 0.6595 \\
\hline Lags: 2 & $f i r$ does not Granger Cause Lnjgdp & 2.6948 & 0.0829 \\
\cline { 2 - 4 } & Lnjgdp does not Granger Cause fir & 7.3300 & 0.0024 \\
\hline
\end{tabular}

表 3 贵州金融发展于贫困减缓: 回归分析 (被解释变量: pov)

\begin{tabular}{|c|c|c|c|c|}
\hline 变量 & 回归模型（1） & 回归模型（2） & 回归模型（3） & 回归模型（4） \\
\hline 常数 & $\begin{array}{c}0.6413 * * * \\
(2.8249)\end{array}$ & $\begin{array}{c}-1.4503 * * * \\
(-7.8414)\end{array}$ & $\begin{array}{l}0.7674 * * * \\
(10.4536)\end{array}$ & $\begin{array}{c}-1.0104 * * * \\
(-3.3117)\end{array}$ \\
\hline Fir & $\begin{array}{l}0.1172 * * * \\
(17.8113)\end{array}$ & & $\begin{array}{c}0.2755 * * * \\
(2.7737)\end{array}$ & \\
\hline$f i r^{2}$ & $\begin{array}{c}-0.0608 * * * \\
(-5.7782)\end{array}$ & & $\begin{array}{c}-0.0809 * * * \\
(-4.1021)\end{array}$ & \\
\hline $\mathrm{Fe}$ & & $\begin{array}{c}3.6469 * * * * \\
(9.8761)\end{array}$ & & $\begin{array}{c}2.9913 * * * \\
(6.1417)\end{array}$ \\
\hline$f e^{2}$ & & $\begin{array}{c}-1.5379 * * * \\
(-8.5945)\end{array}$ & & $\begin{array}{c}-1.2588 * * * \\
(-5.7284)\end{array}$ \\
\hline Lnr jgdp & & & $\begin{array}{c}-0.0344 * * \\
(-2.062)\end{array}$ & $\begin{array}{l}-0.0219 * * \\
(-2.4372)\end{array}$ \\
\hline $\mathrm{Cr}$ & & & $\begin{array}{c}-0.0223 \\
(-1.0093)\end{array}$ & $\begin{array}{c}0.0282 * * * \\
(2.8676)\end{array}$ \\
\hline$R^{2}$ & 0.8896 & 0.9153 & 0.9039 & 0.9329 \\
\hline
\end{tabular}

注： $R^{2}$ 表示拟合优度, ${ }^{* * *}$ 和*分别表示在 $1 \%$ 和 $5 \%$ 的著性显水平上统计显著, 括号内 为各参数估计值的 $\mathrm{t}$ 统计量。 


\section{3. 回归分析}

本文依据模型（1）和模型（2） 并分别以金融发展效率 (fe) 和金融发 展规模 (fir) 作为衡量金融发展水平的 指标进行回归分析, 检验贵州省金融 减贫的非线性效应, 回归结果见表 3 。

回归分析结果显示回归模型 (1) (4) 中金融发展规模 (fir) 和 金融发展效率 $(\mathrm{fe})$ 的系数均是 $\beta 1>$ $0, \quad \beta 2<0$, 说明从直接和间接促进作 用来看，贵州省金融发展与贫困减缓 之间都存在库兹涅茨效应, 验证了 Greenwood \& Jovanovic 的观点。

本文进一步依据回归模型（1）和 回归模型 (2) , 借助 Matlab 软件分 别绘制金融发展规模 (fir) 、金融发展 效率 (fe) 和贫困减缓 (pov) 之间的非线 性关系图。从图 1 和图 2 我们可以更 加直接的看出金融发展与贫困减缓之 间的库兹涅茨 “倒 U 型” 曲线关系。

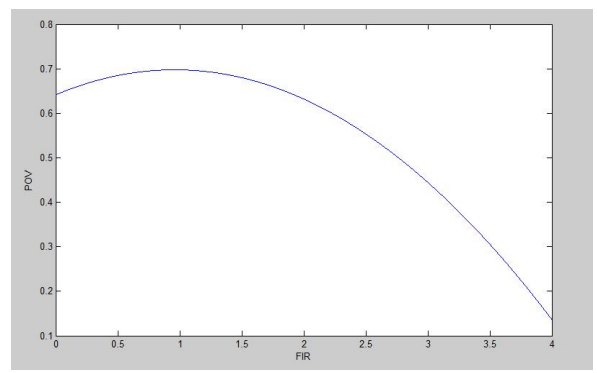

图 1 pov 和 fir 的 “倒U 型” 关系图

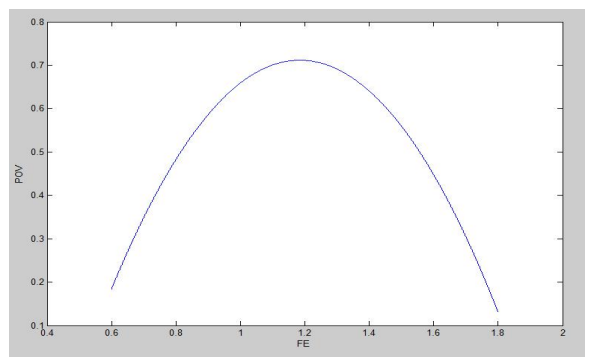

图 2 pov 和 fe 的 “倒 U 型” 关系图

\section{5. 结论分析与政策建议}

本文通过计量分析可以得到如下 结论:

1. 贵州省金融发展与贫困减缓之 间遵循库兹涅茨 “倒 $U$ 型” 曲线的非 线性关系。贵州省由于经济发展水平 低、贫困面广、贫困率高 ${ }^{[12]}$, 经济发 展的落后性使其陷入 “贫困陷阱”。 从而导致在经济发展初期阶段, 因为贫 困人口受到金融服务的门槛限制, 难以 从金融发展中受益; 随着贵州省金融 和经济的发展, 金融服务的门槛逐步增 强降低, 金融发展逐渐有利于贫困减 缓。

2. 现阶段贵州省金融发展对贫困 减缓有积极促进作用。金融在经济运 行中是联系其他部门的纽带, 在资本 形成中起着至关重要的作用。金融通 过中介功能的发挥, 促进储蓄向投资 的转化, 提高资本积累率, 从而促使 经济跳出 “贫困陷阱” 进入更高水平 的均衡状态 ${ }^{[13]}$ 。

综上所述，贵州省在金融扶贫工 作中要扩大对贫困地区和贫困群体的 融资规模。现阶段贵州省贫困地区经 济社会发展存在较大的资金缺口, 因 此有必要增加对贫困地区和贫困群体 的贷款投放，鼓励和引导各类金融机 构扩大贫困地区涉农贷款投放，促进 降低社会融资成本。同时要加大金融 精准扶贫力度。扶贫资金安排要实行 统一规划, 要因贫困原因、因贫困类 型等有针对性的投入，提高扶贫资金 的使用效率，促进贫困地区经济社会 发展。

\section{参考文献}

[1] 黄承伟,叶蹈.脱贫攻坚省级样板: 贵州精准扶贫精准脱贫模式研究 
$[\mathrm{M}]$. 北京: 社会科学文献出版 社,2016.

[2] Akhter S, Liu Y, Daly K. Cross Country Evidence on the Linkages between Financial Development and Poverty[J].2009,5(11):207-214.

[3] Jalilian.H and Kirkpatrick. Growth and Poverty Reduction in Developing Countries[J]. International Journal of Finance and Economics, 2002,7(2):97-108.

[4] Fowowe B , Abidoye B . The effect of financial development on poverty and inequality in African countries[J].Manchester School,2013,81(4):562-585.

[5] Seven U, Coskun Y. Does financial development reduce income inequality and poverty? Evidence from emerging countries[J].Emerging Markets Review, 2016, 26:34-63.

[6] Jeremy Greenwood, Boyan Jovanovic."Financial Development, Growth, and Distribution of Income." [J]. Journal of Political Economy, 1990, 98(5):1076-1107.

[7] 崔艳娟.金融发展与贫因减缓:路 径、效应与政策启示 $[\mathrm{M}]$. 北京:经 济科学出版社,2014.

[8] 苏静,胡宗义,唐李伟.农村非正规 金融发展的减贫效应非线性研 究——基于 PSTR 模型的分析 [J]. 农业技术经济, 2014(1):81-90.

[9] 郑长德.中国西部民族地区的经济 发展[M].北京市:科学出版社,2009.

[10] 张兵,翁辰.农村金融发展的减贫 效应——空间溢出和门槛特征 $[\mathrm{J}]$. 农业技术经济, 2015(9):37-47.

[11] 杨建春,施若.金融支持旅游产业 发展的动态效应比较- - 以贵 州、浙江两省为例 [J].社会科学 家,2014(6):88-92.

[12] 师荣蓉,徐璋勇,赵彦嘉.金融减贫 的门槛效应及其实证检验——基
于中国西部省际面板数据的研究 [J].中国软科学,2013(3):32-41. 